\title{
Spatial Configuration Based on Amount of Communication for Organizational Creativity in Interior Design Firms
}

\author{
Azizah Md Ajis ${ }^{1} \&$ Ryusuke Naka ${ }^{2}$ \\ ${ }^{1}$ Graduate School of Science \& Technology, Kyoto Institute of Technology, Japan \\ ${ }^{2}$ Design Engineering and Management, Kyoto Institute of Technology, Japan \\ Correspondence: Azizah Md Ajis, Naka Lab, Graduate School of Science \& Technology, Kyoto Institute of \\ Technology, Matsugasaki, Sakyo-ku, Kyoto 606-8585, Japan. E-mail: azizahmdajis@gmail.com
}

Received: June 1, 2015 Accepted: July 23, 2015 Online Published: September 29, 2015

doi:10.5539/jsd.v8n8p285 URL: http://dx.doi.org/10.5539/jsd.v8n8p285

\begin{abstract}
This study examined how physical office spaces can support the creation of knowledge related to creativity and to foster a communicative environment. This research aims to determine spatial configurations that can help facilitate communication for knowledge creation processes associated with creative works by focusing on knowledge creation behaviors (SECI Model), the amounts of communication, and social networks as the dimensions for measurement. Using the case study approach, this cross-sectional study examined two small-scale interior design firms in Malaysia. Space syntax VGA analysis was used to identify the potential space that would facilitate a communicative environment. Ethnographic methods were used to examine the empirical evidence, while semi-structured interviews were used to derive the SECI behaviors performed in creative organizations such as the firms in the case studies. The findings showed various spatial configurations and usage depending on the communication occurrences of SECI behaviors. Since organizations place high expectations on increasing knowledge productivity, the knowledge gained from this study can help workplace planners to propose suitable spaces according to an organization's work culture.
\end{abstract}

Keywords: creativity, workplace communication, spatial configuration, knowledge creation

\section{Introduction}

\subsection{Background}

After going through of the hunting and gathering age agricultural, the agricultural age and the industrial ages, the global economic life has entered its fourth stage - which is known as the "information age. Furthermore, some even suggested that the world is now entering the fifth era called the "creative age." In order to survive and remain competitive in this era, many businesses have strategically encourage organizational creativity as a way to keep abreast with the economic changes. Organizational creativity is the process of associating, developing, and rearranging knowledge to generate new knowledge; this can deliver values in forms of products, ideas, systems, processes, or services created by individuals working together in a complex social system (Gurteen, 1998; Koh, 2000; Woodman, Sawyer, \& Griffin, 1993).

Many concerns have also been raised about how organizational creativity can be encouraged in the workplace. This is because encouraging organizational creativity requires an understanding of its process. The process in organizational creativity, begins with generating the creation, followed by disseminating and leveraging the process until the organization's objectives are fulfilled. Many scholars have noted that organizational elements such as dynamic interactions, motivation, social implications, skills, abilities, task complexity, organizational culture and climate, as well as technological and spatial environments can affect creativity in the workplace (Girdauskiene, 2013; Kallio, Kallio, \&Blomberg, 2015; Koh, 2000; Martens, 2011; Sailer, 2011). Meanwhile, the discussion in this present study focuses specifically on spatial environment as the factor affecting creativity in the workplace.

\subsection{Creativity in the Workplace and Knowledge Creation}

"Creativity" is often conflated with "innovation." In this study, "creativity" in the workplace is defined as the complex combination of cognitive, motivational, and emotional processes that are associated with exploring ideas, thinking, planning, making decisions, exchanging ideas, and developing new knowledge. On the other 
hand, "innovation" is defined as the process of sifting, refining, and turning and the ideas into implementation that can be rendered into some kind of tangible forms (a product, service, etc.). Some scholars have suggested that there are four phases in the creative process (Wallas, 1926, in Kristensen, 2004; Martens, 2011). These phases are preparation, which is the process of gathering information and data about the problem or creation from all directions; incubation, the process of development, continuous thinking, and implicit cognition, insight. the appearance and understanding of the idea, which helps solve the problem or creation; and elaboration and evaluation, where the creation or solution to the problem is tested for its validity to determine whether it has met the objective and has any value. However, these processes cannot be generated without identifying the knowledge that is recognized through individual artistic creativity, skills, and talents, which lead to new knowledge creation as well as continuous innovation through individual and collaborative cognitive tasks. Based on these circumstances, the whole process of creativity is associated with its basic root in reference to the knowledge creation processes. These processes are parts of knowledge management, specifically, the knowledge creation model developed by Nonaka and Takeuchi (1995). This model advocated that knowledge creation is a process in which organizations create knowledge and where two types of knowledge, explicit and tacit, mutually interact and continually rise in a dynamic spiral, ontologically from the low levels of individuals to the high levels in the organization. This process has been presented in terms of four modes of knowledge conversion, which are socialization, externalization, combination, and internalization (SECI). Based on the SECI model, NOPA (Nihon Office Promotion Association) has extended the analysis by developing 12 SECI behaviors (Figure 1) to determine knowledge creation processes in creative organizations (e.g., R\&D firms, architecture firms, interior design firms, advertising companies, and many others).

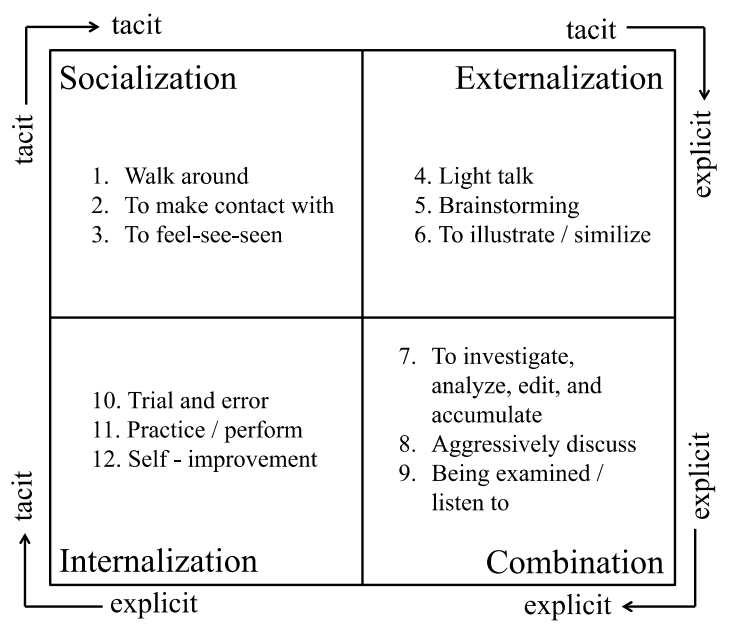

Figure 1. Knowledge creation behavior matrix

\subsection{Amount of Communication, Interaction Patterns, and Spatial Configuration}

Knowledge creation processes associated with creativity in the workplace are highly and cognitively dependent on effective communication among the organizational members. Through effective communication, organizational members from various teams and departments can increase the positive impacts of cross-fertilization in generating new knowledge, ideas, and insights, as well as information exchanges between them. Some scholars agreed that the increase in communication helps facilitate the process when organizational members use their cognitive abilities to explore knowledge creation processes associated with creativity (Large, 2005; Mueller \& Lee, 2002; Stryker, Santoro, \& Farris, 2012; Zimmermann, Sypher, \& Haas, 1996). These authors also claimed that a boost in communication among team members encourages information exchange, reduces uncertainty and ambiguity, and improves the quality of the information and satisfaction in the communications. However, the increased in communication can also have negative influences by creating distractions (Leenders, Van Engelen, \&Kratzer, 2003). For example, communication overload can adversely affect the momentums and enthusiasms for creative and innovative ideas. On the other hand, since this study seeks to explore the characteristics of spatial configuration that can foster creativity, it has been hypothesized that the increase in communication might be beneficial to foster creativity.

This study examines how physical office spaces can support knowledge creations related to creativity and how they can foster a communicative environment (Häkkinen \& Nuutinen, 2007) and develop sustainability. 
Determining the spatial configurations of office layouts may provide insights into how to support activities that promote knowledge creations related to creativity. There are many perspectives regarding how spatial configuration can support creativity, however, much of the research in this area has focused only on spatial configuration as one of the many factors that contribute to improvement in the work environment (Martens, 2011; Sailer, 2011; Toker\& Gray, 2008). In this study, spatial configuration can be defined as the patterns or forms, arrangements, and allocations of space in the office layout. The characteristics of the spatial configurations in the offices can affect communication in terms of frequency and duration. For instance, Boutelier (Boutelier et al., 2008) measured interactions among managers in an R\&D firm and found that managers communicated three times more frequently in shorter periods when they are in multi-use spaces as compared with when they are in their private offices. Furthermore, variables such as "visibility," have been found to promote team and inter-team communications (Hatch, 1987; Stryker, Santoro, \& Farris, 2012), as well as "proximity," where communication increases when the physical distances between workers are smaller (Oldham \& Rotchford, 1983). These variables can positively affect knowledge creation processes that are conducive to organizational creativity. In general, the visibility factor, particularly in the workstation areas, can increase spontaneous communications, while the proximity factor reveals that communication will decrease as physical distances increase.

Despite the rich interpretive discourses on the organizational elements that can galvanize creativity behaviors, some scholars have noted that there is still insufficient data on the association between physical spaces and communication with creative behavior (Greene \& Myerson, 2011; Kallio et al., 2015; Kristensen, 2004; Martens, 2011; Sailer, 2011). Therefore, this study investigates the affects of physical spaces in communication by identifying the characteristics of spatial configurations that encourages organizational members to leverage their creativity by focusing on communication in the knowledge creation process.

\subsection{Aims and Significance}

This study aims to answer the following questions, "what kind of spatial settings has the potential to facilitate a strong communicative environment for knowledge creation processes?' 'What are designers' preferred spatial settings when conducting knowledge creation activities associated with creativity?' And finally, ' With whom do designers interact in those particular spatial settings when performing knowledge creation processes?' Based on these research questions, this study aims to determine the spatial configurations that best facilitate communication for knowledge creation processes related to creative works. Many organizations have high expectations for the increase of knowledge productivity, so providing optimal communicative spaces for creativity-related knowledge creation is expected. Hence, identifying how space is being used for communication in creating knowledge can help improve the effectiveness and efficiency of spatial use. This consideration may aid facilities managers or workplace planners in proposing suitable spaces that are in accordance to the organization's work culture.

\section{Method}

\subsection{Office Layout}

This qualitative research has adopted the case study approach focusing on two creative industry firms. These firms are small-scale Malaysian interior design firm (ORG1 and ORG2, they were chosen because they rely on human capital and the use of knowledge and creativity as their primary production factors (Figure 2). ORG1 has approximately $272.34 \mathrm{msq}$ of work spaces while ORG2 had approximately $131.89 \mathrm{msq}$. The layout in each organization's office had been designed according to the firms' preferences, equipped with computers, furniture, telephones, and standard office materials and equipment. Both offices provide individual workstations without high partitions for their workers. The areas investigated can be divided into individual working territories, meeting territories, and service territories. An individual working territory consists of individual workstations or individual rooms, while the meeting territory can include meeting rooms, reception/waiting rooms, and discussion spaces, meanwhile, the service territories include photocopier/printer corners, libraries, material preparation spaces, and showrooms. 


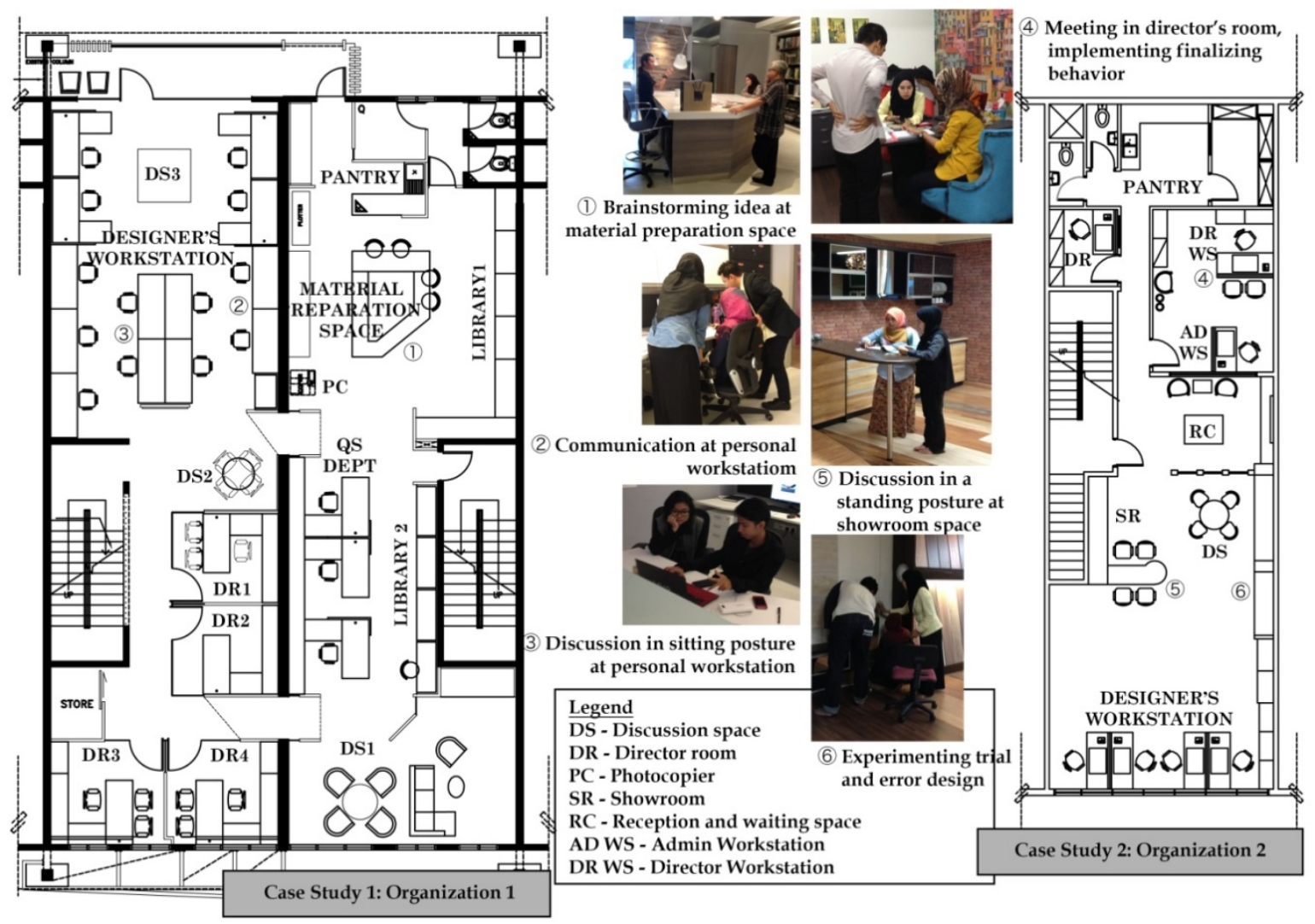

Figure 2. Investigated spatial settings of SECI communication in two case studies

\subsection{Investigation}

The investigation comprised of two stages. First, semi structured interviews were conducted to identify the activities that fall under SECI behaviors. Four respondents from ORG1 and three from ORG2 have volunteered for the interview. The inputs from the interviews were transcribed and then, the data was codified using the thematic qualitative analysis method following the 12 SECI behavior codes. Second, an ethnographic method was used to empirically observe the existing situations in each organization. Observations at both the organizations took place during office hours from 8:30 a.m. until 6:00 p.m., for three consecutive days, September 24-26, 2014, for ORG1, and September 18-22, 2014, for ORG2. A total of 63 hours and 593 communications were recorded. Ten test subjects were observed in ORG 1 and five in ORG 2. The observation procedure consisted of three steps, first, all test subjects were told about the purpose of the study and the type of information that would be collected during the observation, then, one observer was assigned to monitor two test subjects at once by standing at one objective point to ensure that the two test subjects could be seen and their exchanges can be relatively understood and finally, after each communication took place, each test subject was asked about information that are relevant to SECI behaviors, and this data was recorded in the observation sheet.

The data analysis for this study was performed in three ways, the thematic qualitative analysis of data derived from the interviews, the analysis of the spatial properties of the office layout using space syntax analysis to determine spaces with the potential to encourage communicative environments and lastly, an investigation on the tangible behaviors of the organizational members which involved observing the communication that happened and the spaces used in relation to SECI behaviors. In addition, the occurrences of network relationships were also analyzed to identify the spaces used according to the workers' positions when communicating for knowledge creation processes.

\subsection{Analysis}

The flow of the analysis conducted in this study, is shown in Figure 3 while the details of the analyses conducted in this study are presented in the following subsections. 


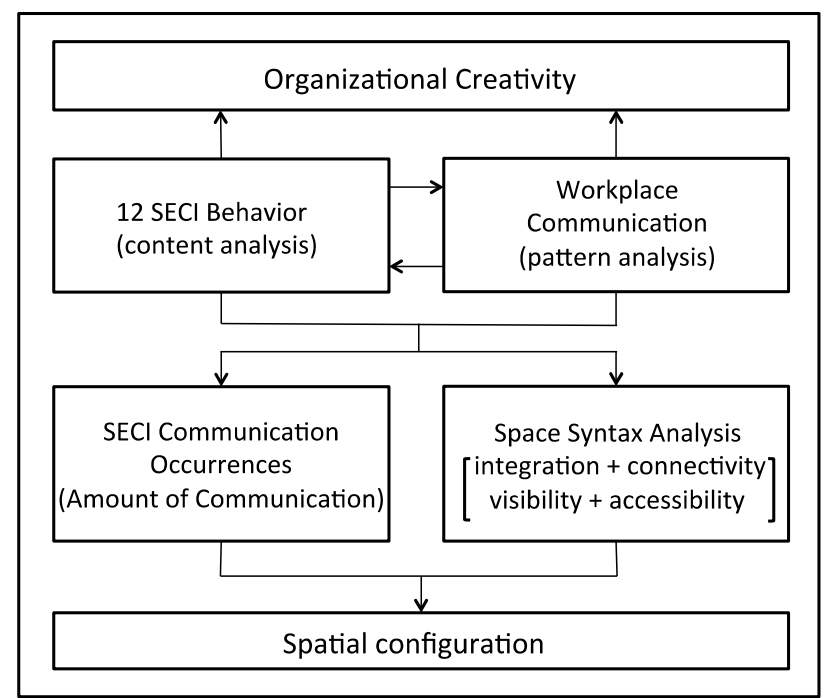

Figure 3. Diagram of the flow of analysis

\subsubsection{Qualitative Analysis}

The following are the objectives of this study, first, knowledge creation processes that occurred were identified using thematic qualitative analysis of the data from the interview transcripts and the summary is shown in Figure 4.

\begin{tabular}{|c|c|c|c|}
\hline & SECI PROCESSES & $\begin{array}{l}12 \text { SECI BEHAVIOR } \\
\text { CODE }\end{array}$ & ACTIVITIES (keywords) \\
\hline \multirow{6}{*}{ Z } & \multirow{3}{*}{$\begin{array}{l}\text { Socialization } \\
\text { stimulating }\end{array}$} & Walk around & $\begin{array}{|cc|}\begin{array}{c}\text { Oversea visit } \\
\text { Furniture fair } \\
\text { Wanit design exhibition } \\
\text { Interior design fair }\end{array} \\
\end{array}$ \\
\hline & & To make contact with & $\begin{array}{ll}\text { Sharing experience } & \text { Develop human network } \\
\text { Knowledge sharing } & \text { Exchange information } \\
\end{array}$ \\
\hline & & To feel-see-seen & $\begin{array}{c}\text { Visiting \& meeting at site Factory visit } \\
\text { Site measurement } \\
\text { Monitoring and observing project }\end{array}$ \\
\hline & \multirow{3}{*}{$\begin{array}{c}\text { Externalization } \\
\text { idea }\end{array}$} & Light talk & $\begin{array}{l}\text { Project talk Briefing ideas Opinion } \\
\text { Advice Negotiation Consultation }\end{array}$ \\
\hline & & $\begin{array}{c}\text { Formal / informal } \\
\text { brainstorm }\end{array}$ & $\begin{array}{l}\text { Brainstorming ideas } \quad \text { Workshop } \\
\text { Searching methods \& problem solution } \\
\text { Obtain data / design requirement } \\
\end{array}$ \\
\hline & & $\begin{array}{l}\text { To illustrate / } \\
\text { similize }\end{array}$ & $\begin{array}{lc}\text { Interpret ideas } & \text { Sketches } 3 \mathrm{D} \\
\text { Work on PC alone } & \text { Express thought } \\
\end{array}$ \\
\hline \multirow[t]{6}{*}{ 受 } & \multirow{3}{*}{$\begin{array}{l}\text { Combination } \\
\text { finalizing }\end{array}$} & $\begin{array}{l}\text { To investigate, analyze, } \\
\text { edit and accumulate }\end{array}$ & \begin{tabular}{lc}
\multicolumn{2}{c}{ Preparing material/documents } \\
Search engine/data & Gathering data \\
Organizing data & Investigate specification \\
Office's library & Layout drawing \\
Perspective drawing & Concept images \\
Tender document & Material Specification \\
\end{tabular} \\
\hline & & $\begin{array}{l}\text { Aggressive } \\
\text { discussion }\end{array}$ & 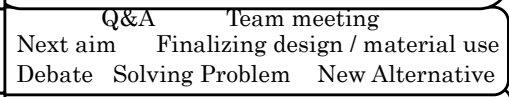 \\
\hline & & $\begin{array}{l}\text { Being examined / } \\
\text { Being listen } \\
\text { Listen to } \\
\end{array}$ & $\begin{array}{c}\begin{array}{c}\text { Reporting progress } \\
\text { Site meeting }\end{array} \\
\begin{array}{c}\text { Technical meeting } \\
\text { Periodical report }\end{array} \\
\end{array}$ \\
\hline & \multirow{3}{*}{$\begin{array}{l}\text { Internalization } \\
\quad \text { improve } \\
\text { understanding }\end{array}$} & Make a trial & $\begin{array}{c}\text { Trial \& error design } \\
\text { On-site design experiment } \\
\text { Computer simulation } \\
\end{array}$ \\
\hline & & Practice / perform & $\begin{array}{l}\text { Presenting design proposal Walk-in customer } \\
\text { Product Display Explanation } \quad \text { Past Project }\end{array}$ \\
\hline & & $\begin{array}{c}\text { Improve } \\
\text { understanding }\end{array}$ & $\begin{array}{|cc|}\text { Self-observation } & \text { Factory tour } \\
\text { Internal workshop } & \text { Visit similar project } \\
\text { Product presentation by supplier } \\
\text { Attend seminar/ skill enhancement class } \\
\text { Communication with expert Seeking advice }\end{array}$ \\
\hline
\end{tabular}

Figure 4. Organizational knowledge creation behavior based on qualitative analysis from interviews 


\subsubsection{Visibility Graph Analysis: Accessibility and Visibility}

For the second analysis, a visibility graph analysis (VGA) under space syntax was used to explore the concepts and the spatial properties of "accessibility" and "visibility" in both the office layouts. The measurements used were "integration value" and "connectivity value." Even though there is a broad range of methodologies on the use of space syntax in determining spatial configuration, VGA analysis was chosen because of its relevance to the context of visibility and accessibility in the form of visualization. VGA is used to describe the configurational properties of space by analyzing the inter-visibility connections within buildings, and in this study, VGA was used as the manifestation of the spatial perception of space usage. In the first stage, the software 'Depthmap' (Turner, 2001) was used to create and analyze visibility graphs. The grid resolution that was used to analyze all offices was $200 \times 200 \mathrm{~mm}$, and isovists were created from the very center, or point locations of the grid squares. This resolution was selected since it can cover all the narrowest spaces in the furniture locations. This visibility graph was applied and analyzed for each office; hence, there were two different representations of VGA investigated. The first was accessibility, which means the potential for the flow of movement, hence, the visibility graph based on accessibility was analyzed at the knee level based on the perceptive of an individual walking around the building and communicating with others; thus, all solid walls, furniture, glass walls, partitions etc., were modeled as barriers (as shown in accessibility graph in Figure 5). The second representation was visibility, this representation was based on the assumption that communication would occur based on the co-presence and visibility of other researchers. Here, the visibility graph was analyzed at eye level; thus, only solid walls, high partitions, and high cabinets were modeled as barriers (see visibility graph in Figure 5). These VGA measures also used two types of measurements, which are visual connectivity and visual integration. Visual connectivity is the number of locations that can be connected, while visual integration concerns how integrated or segregated the spaces is in the whole building is. Figure 5 shows the VGA maps for both offices in terms of the accessibility and visibility representations of the layouts. Spatial points are visualized on the maps using a red-to-blue color scheme. Areas of high intensity like integrated areas and areas with high connectedness are shown in warm colors such as red, orange, yellow and areas of low intensity like segregated areas and areas with low connectedness are shown in cool colors like green and blue.

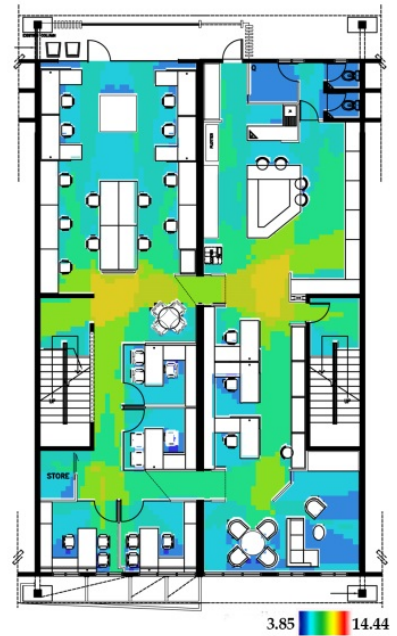

ORG 1 accessibility graph

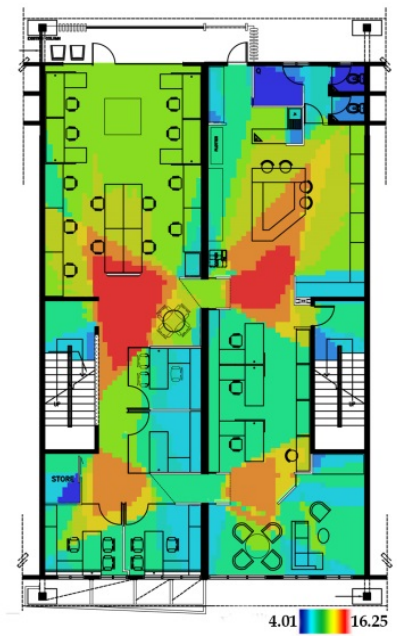

ORG 1 visibility graph
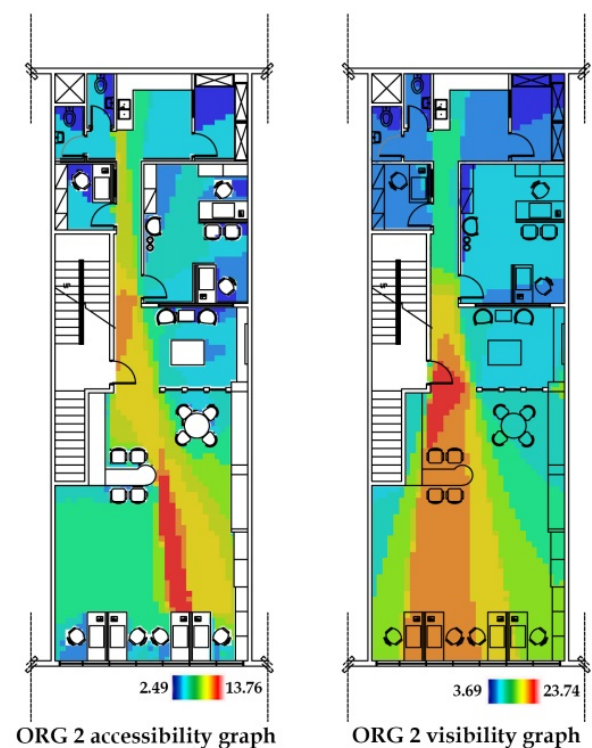

Figure 5. VGA graphs of accessibility and visibility for both case studies

\subsubsection{Statistical Analysis of Amount of SECI Communication}

Descriptive analysis using Microsoft Excel 2013 was used in the third analysis. The results are shown in Table 2, Figure 6 and Figure 7.

\section{Results and Discussion}

\subsection{The 12 SECI Behaviors and Activities in Creative Organization}

The qualitative data analysis of the interviews sought to identify knowledge creation behaviors in creative 
organizations such as interior design firms. Data derived from the interview transcripts were sorted according to the 12 SECI behavior codes as developed by NOPA in their study on creative offices. The keywords that represent activities performed during the whole process of knowledge creation were codified into SECI behavior codes under their respective categories (Figure 3).

\subsection{Spatial Configuration for Potential Communicative Spatial Settings}

In the VGA maps, we hypothesized that red-colored spatial points would have high possibilities for communication; hence, they are called 'AOC' which stands for communicative space, since the space was well integrated. Meanwhile, the blue-colored spaces had low communicative possibilities because of their segregated locations. The findings of the mean value for integration and mean value of connectivity in both offices are shown in Table 1.

Table 1. Space syntax spatial properties in both case studies

\begin{tabular}{lrr}
\hline Office & ORG 1 & ORG 2 \\
\hline Mean Connectivity (Accessibility) & 1400.17 & 546.61 \\
Mean Integration (Accessibility) & 8.62 & 7.37 \\
Mean Connectivity (Visibility) & 1642.59 & 1211.12 \\
Mean Integration (Visibility) & 10.56 & 12.61 \\
\hline
\end{tabular}

From the analysis results, both offices showed high integration values (ORG1 Int.V=8.63; ORG2 Int.V=7.37), this means that both layouts had well-connected spaces. In terms of the accessibility in both offices, the integrated spaces were mostly found in circulation areas (ORG1 Int.V=6.19; ORG2 Int.V=9.05). On the other hand, for "visibility," ORG 1 has shown high integration values (Int.V=5.34) for its material preparation spaces, photocopier (Int. $\mathrm{V}=5.82$ ), and circulation spaces within the meeting points of workstations and discussion spaces Meanwhile, ORG 2's integrated space showed high values for the showroom (Int.V=9.08) and circulation spaces (Int.V=9.05). Based on these findings, we hypothesized that communicative possibilities for knowledge creation processes would be high in the indicated areas. The actual communications occurrences are analyzed and compared in the next analysis.

\subsection{Spatial Use in Knowledge Creation Behaviors Based on AOC and Social Network Relationships}

Descriptive analysis was used to fulfill the objectives of examining the relationship between SECI behavior communication and social network relationships, examining the efficiency of spatial use for SECI behavior by measuring spatial occupancy during communication over time; and finally, examining the communicative environment that fosters knowledge creation in creative organizations by comparing VGA spatial configurations, based on accessibility and visibility with spatial use based on the observation conducted.

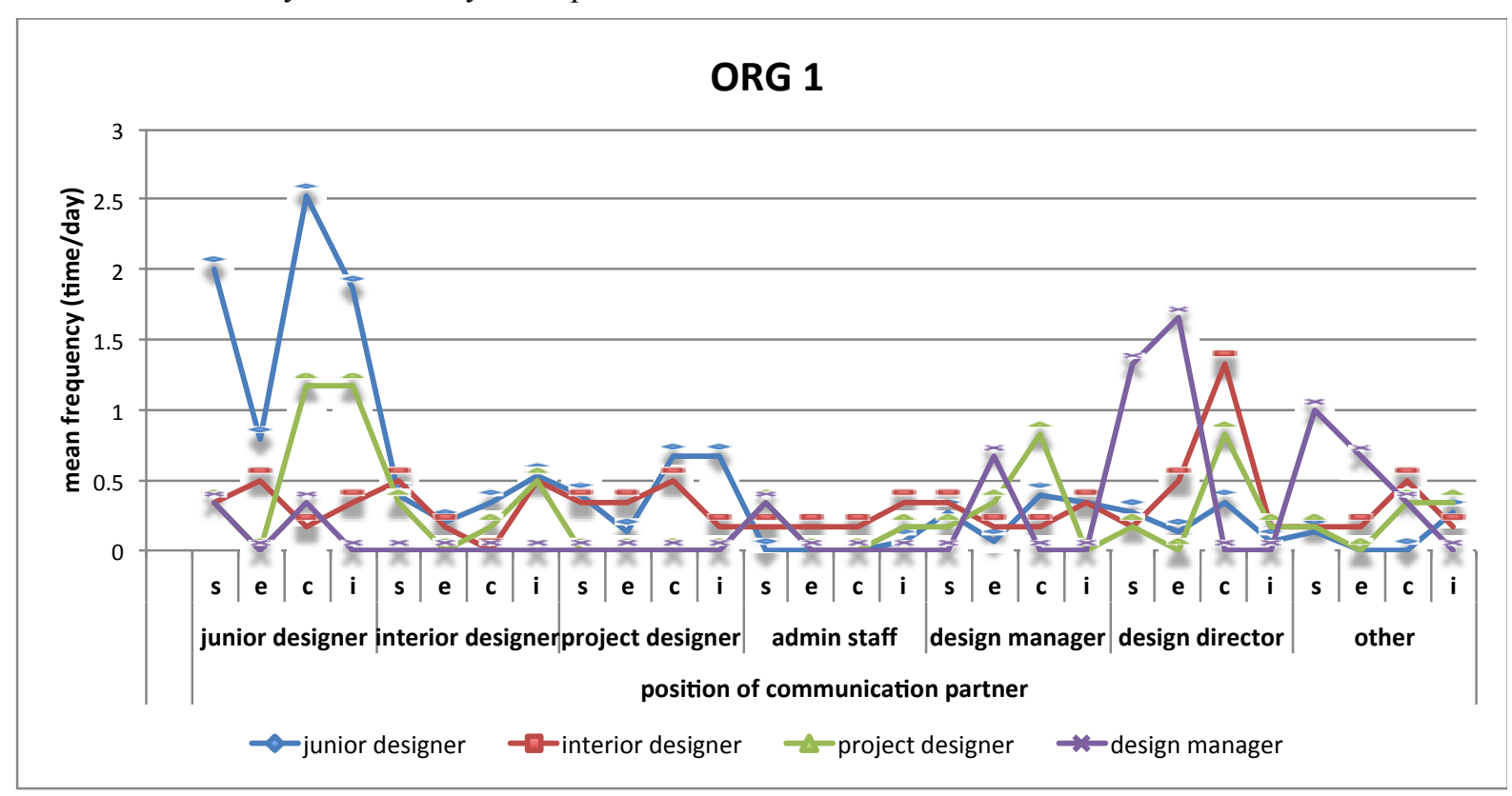


(graph continued)

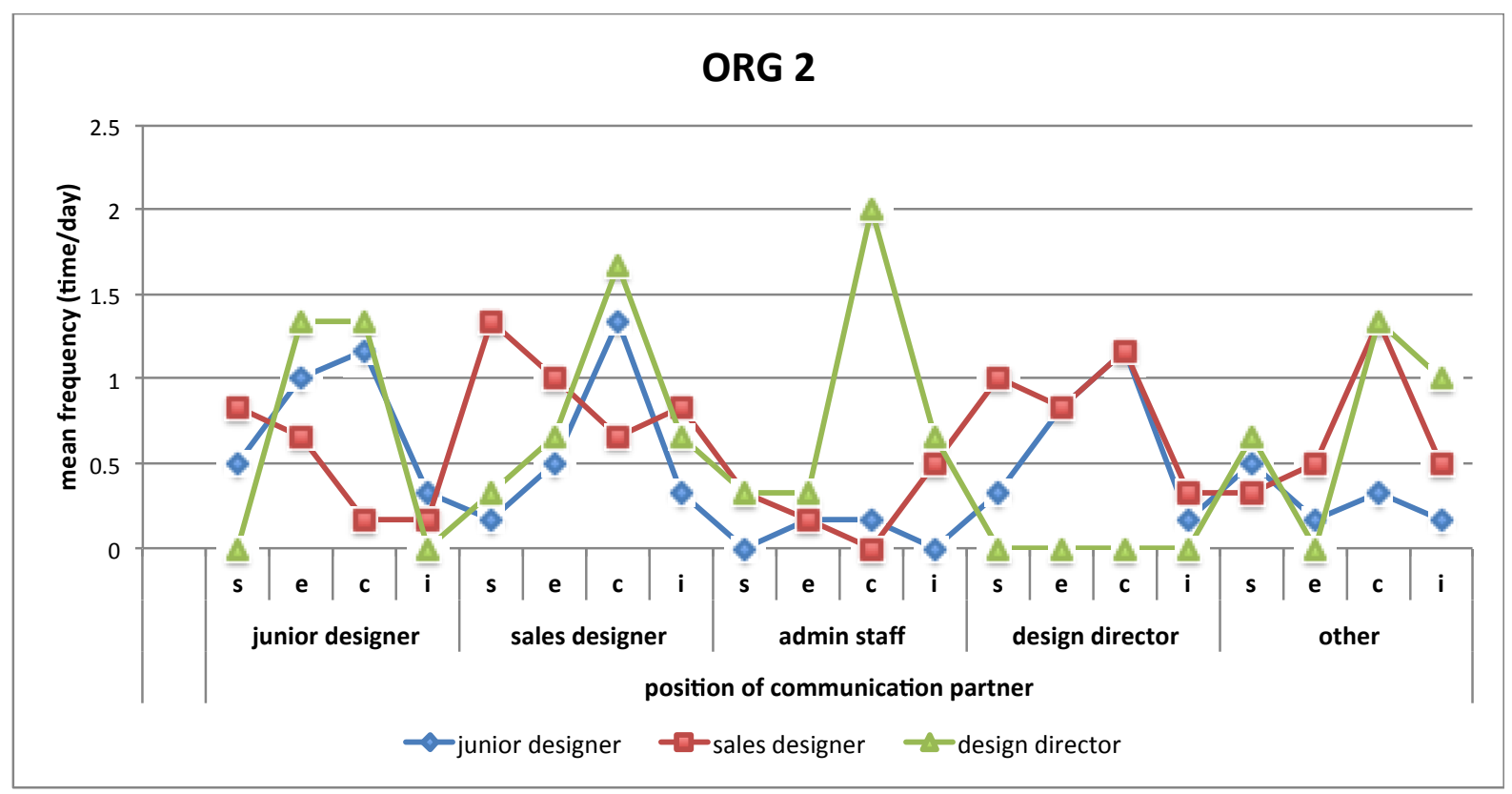

Figure 6. The mean frequency of communication (time/day) with communication partner per worker

For the first objective (see Figure 6), descriptive analysis was conducted by determining the mean frequency (time/day) of communication that occur for each worker during office hours ( 8 hours). For ORG 1, the analysis result showed that junior designers had the most AOC with their colleagues who are at the same level, with an average of $f=2.53$ communication occurrences per day during combination processes; combination processes involved finalizing behaviors where activities such as the preparation of documents on tenders and proposals took place. Meanwhile, interior designers had about $f=1.33$ occurrences with the design director during combination processes, while project designers had an average of $f=1.17$ for both combination and internalization processes with junior designers. At this stage, interior designers usually have discussions regarding the progress of the work and disputes that occur at the site and in the mean time, also to seek advice regarding the alternative solutions or opinions regarding design matters. These results also stemmed from the interactions with junior designers who sought advices on their work or wanted to learn something new; this can be categorized under the internalization processes. Lastly, the design managers had the most AOC with the design director, averaging at $f=1.67$ communication occurrences per day in externalization processes. As for ORG 2, junior designers had the most communication occurrences with sales designers at $\mathrm{f}=1.33$ per day during the combination processes. On the other hand, sales designers had an average of $\mathrm{f}=1.17$ communications per day with the design director during combination processes. Finally, the design director averaged at $f=2.00$ of AOC during combination processes with the administrative staffs. Although the mean frequency showed higher values, the content of communication with administrative staff was mostly related to management work rather than creative work. The design director also had a high mean frequency with sales designers, averaging at $f=1.67$ communications per day. The activities involving sales designers leaned more towards the 'aggressively discuss' behaviors (see Figure 4). Based on these results, it can be concluded that the social network in both of the organizations can be divided into three levels: junior, senior, and superior. The junior level had more SECI communication with individual in the same level during the combination processes, while senior designers had the most SECI communication with their superiors and junior levels workers, mostly during combination and internalization processes. Lastly, the superior level workers had the most dominant communication with senior designers during the socialization, externalization, and combination processes.

For the second objective (see Table 2), the sum of the mean frequency of communication occurrences in each of the cluster was calculated. Time clusters were further categorized into four time lengths: less than 1 minute $(<1$ minute), 1 to 5 minutes, 6-30 minutes, and more than 30 minutes ( $>30$ minutes). In ORG 1 , communication frequently occurred in combination behaviors with duration of $1-5$ minutes at the studio workstations, director/manager rooms, and the QS division workstations, while socialization behaviors frequently occurred in 
the discussion, photocopier, and circulation spaces for 1-5 minutes. These results are attributed to the spontaneous communication and discussions that were predominantly focused on a new project that was in the initial design stage during the observation. On the other hand, ORG 2 showed frequent communication during combination behaviors at designer workstations, discussion spaces, reception/waiting spaces, and circulation spaces for 1-5 minutes. Externalization behaviors frequently occurred in discussion spaces for ORG 1, and the same behaviors frequently occurred in reception/waiting spaces for ORG 2 in the range of 6-30 minutes. These circumstances were attributed to discussions of client requirements since the space was created for the purpose of entertaining clients and designed with comfortable ambience and furniture. Finally, instances of communication that lasted for more than 30 minutes $(>30 \mathrm{~min})$ mostly took place at individual working territories in both of the organizations and the activities fall under the externalization and combination processes. Most of these activities were related to the generating of ideas for a new project and discussions about finalizing a design proposal that was going to be presented to a client.

Table 2. Spatial properties, amount of SECI communication, and space used

\begin{tabular}{|c|c|c|c|c|c|c|c|c|c|c|c|c|c|c|c|c|c|c|c|c|c|c|c|}
\hline \multirow{3}{*}{ item } & \multirow{3}{*}{ spatial settings } & \multicolumn{2}{|c|}{ SS SPATIAL PROPERTIES } & \multicolumn{20}{|c|}{ DURATION } \\
\hline & & \multirow{2}{*}{\begin{tabular}{|c|} 
cccessibility \\
$\begin{array}{c}\text { integration } \\
\text { value }\end{array}$ \\
\end{tabular}} & \multirow{2}{*}{$\begin{array}{c}\text { visibility } \\
\begin{array}{c}\text { integration } \\
\text { value }\end{array}\end{array}$} & \multicolumn{5}{|c|}{$<1$ minute } & \multicolumn{5}{|c|}{$1-5$ minutes } & \multicolumn{5}{|c|}{$6-30$ minutes } & \multicolumn{5}{|c|}{$>30$ minutes } \\
\hline & & & & $S$ & $\mathrm{E}$ & C & I & sum & $S$ & E & C & I & sum & $S$ & $E$ & C & I & sum & $S$ & $\mathrm{E}$ & C & I & sum \\
\hline \multirow{9}{*}{ 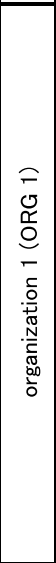 } & studio's workstation & 4.88 & 11.20 & $\begin{array}{c}3.67 \\
(0.58)\end{array}$ & $\begin{array}{c}1.00 \\
(1.73)\end{array}$ & $\begin{array}{c}7.67 \\
(6.35)\end{array}$ & $\begin{array}{c}2.00 \\
(1.73)\end{array}$ & $\begin{array}{l}14.33 \\
(7.57)\end{array}$ & $\begin{array}{l}13.67 \\
(4.16)\end{array}$ & $\begin{array}{c}6.00 \\
(3.61)\end{array}$ & \begin{tabular}{|l|}
17.67 \\
$(9.61)$
\end{tabular} & $\begin{array}{l}12.33 \\
(7.77)\end{array}$ & \begin{tabular}{|l}
49.67 \\
$(22.7)$
\end{tabular} & $\begin{array}{c}1.33 \\
(1.16)\end{array}$ & $\begin{array}{c}1.33 \\
(1.16)\end{array}$ & \begin{tabular}{|c|}
1.33 \\
$(0.58)$ \\
\end{tabular} & \begin{tabular}{|c|}
2.67 \\
$(4.62)$
\end{tabular} & \begin{tabular}{|c|}
6.67 \\
$(5.69)$
\end{tabular} & & & \begin{tabular}{|c|}
0.33 \\
$(0.58)$
\end{tabular} & & \begin{tabular}{|c}
0.33 \\
$(0.58)$
\end{tabular} \\
\hline & director / manager room & 4.69 & 8.87 & $\begin{array}{c}0.33 \\
(0.58)\end{array}$ & & $\begin{array}{c}0.33 \\
(0.58)\end{array}$ & & $\begin{array}{c}0.67 \\
(1.16)\end{array}$ & \begin{tabular}{|c|}
0.33 \\
$(0.58)$ \\
\end{tabular} & $\begin{array}{c}0.33 \\
(0.58) \\
\end{array}$ & \begin{tabular}{|c|}
1.67 \\
$(1.53)$
\end{tabular} & \begin{tabular}{|c|}
0.67 \\
$(0.58)$
\end{tabular} & \begin{tabular}{|c}
3.00 \\
$(1.73)$ \\
\end{tabular} & & $\begin{array}{c}0.33 \\
(0.58)\end{array}$ & $\begin{array}{c}0.33 \\
(0.58)\end{array}$ & $\begin{array}{c}0.33 \\
(0.58)\end{array}$ & $\begin{array}{c}1.00 \\
(1.00)\end{array}$ & & \begin{tabular}{|c|}
0.33 \\
$(0.58)$
\end{tabular} & $\begin{array}{c}0.33 \\
(0.58)\end{array}$ & & \begin{tabular}{|c|}
0.67 \\
$(0.58)$
\end{tabular} \\
\hline & QS Division's workstation & 4.64 & 9.72 & & & & & & \begin{tabular}{|c|}
0.33 \\
$(0.58)$ \\
\end{tabular} & $\begin{array}{c}0.33 \\
(0.58) \\
\end{array}$ & $\begin{array}{c}1.00 \\
(1.00) \\
\end{array}$ & & $\begin{array}{c}1.67 \\
(1.16) \\
\end{array}$ & & $\begin{array}{c}0.33 \\
(0.58) \\
\end{array}$ & \begin{tabular}{|c|c}
0.33 \\
$(0.58)$ \\
\end{tabular} & & \begin{tabular}{|c|}
0.67 \\
$(0.58)$ \\
\end{tabular} & & & & & \\
\hline & discussion space & 5.02 & 11.28 & \begin{tabular}{|c|}
0.67 \\
$(0.58)$
\end{tabular} & & & & $\begin{array}{c}0.67 \\
(0.58) \\
\end{array}$ & $\begin{array}{c}2.00 \\
(1.00)\end{array}$ & \begin{tabular}{|c|}
0.67 \\
$(0.58)$
\end{tabular} & $\begin{array}{c}0.33 \\
(0.58)\end{array}$ & \begin{tabular}{|c}
0.33 \\
$(0.58)$
\end{tabular} & $\begin{array}{c}3.33 \\
(1.16) \\
\end{array}$ & $\begin{array}{c}0.33 \\
(0.58) \\
\end{array}$ & \begin{tabular}{|c|}
0.67 \\
$(0.58)$
\end{tabular} & & & $\begin{array}{c}1.00 \\
(0)\end{array}$ & & & & \begin{tabular}{|c|}
1.67 \\
$(2.89)$
\end{tabular} & $\begin{array}{c}1.67 \\
(2.89)\end{array}$ \\
\hline & material preparation space & 5.34 & 13.04 & & & & & & & & $\begin{array}{c}0.33 \\
(0.58) \\
\end{array}$ & & $\begin{array}{c}0.33 \\
(0.58) \\
\end{array}$ & & & $\begin{array}{c}0.33 \\
(0.58) \\
\end{array}$ & & \begin{tabular}{|c|}
0.33 \\
$(0.58)$ \\
\end{tabular} & & & & & \\
\hline & photocopier & 5.82 & 11.06 & & & \begin{tabular}{|c|c}
0.33 \\
$(0.58)$ \\
\end{tabular} & & \begin{tabular}{|c|c}
0.33 \\
$(0.58)$ \\
\end{tabular} & \begin{tabular}{|c|}
0.67 \\
$(1.16)$ \\
\end{tabular} & & & & $\begin{array}{c}0.67 \\
(1.16) \\
\end{array}$ & & & & & & & & & & \\
\hline & library & 6.19 & 10.68 & & & & & & & & & & & \begin{tabular}{|c|}
0.33 \\
$(0.58)$ \\
\end{tabular} & $\begin{array}{c}0.33 \\
(0.58) \\
\end{array}$ & & & \begin{tabular}{|c|}
0.67 \\
$(1.16)$
\end{tabular} & & & & & \\
\hline & pantry & 3.92 & 10.01 & & & & & & & & & & & & $\begin{array}{c}0.33 \\
(0.58)\end{array}$ & & & \begin{tabular}{|c|}
0.33 \\
$(0.58)$
\end{tabular} & & & & & \\
\hline & circulation & 6.19 & 12.48 & $\begin{array}{c}0.33 \\
(0.58) \\
\end{array}$ & & \begin{tabular}{|c}
0.33 \\
$(0.58)$ \\
\end{tabular} & & $\begin{array}{c}0.67 \\
(0.58) \\
\end{array}$ & $\begin{array}{c}0.67 \\
(0.58)\end{array}$ & & & & $\begin{array}{c}0.67 \\
(0.58) \\
\end{array}$ & $\begin{array}{c}0.33 \\
(0.58) \\
\end{array}$ & & & & \begin{tabular}{|c|}
0.33 \\
$(0.58)$ \\
\end{tabular} & & & & & \\
\hline \multirow{8}{*}{ 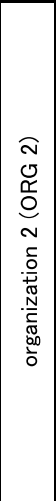 } & designer's workstation & 6.78 & 17.78 & \begin{tabular}{|c|}
3.00 \\
$(3.00)$ \\
\end{tabular} & $\begin{array}{c}1.00 \\
(1.73) \\
\end{array}$ & \begin{tabular}{|c}
3.33 \\
$(0.58)$ \\
\end{tabular} & $\begin{array}{c}1.00 \\
(0) \\
\end{array}$ & \begin{tabular}{|c|}
8.33 \\
$(4.51)$ \\
\end{tabular} & \begin{tabular}{|c}
3.00 \\
$(1.00)$ \\
\end{tabular} & $\begin{array}{c}3.33 \\
(2.08) \\
\end{array}$ & \begin{tabular}{|c|}
6.67 \\
$(3.06)$ \\
\end{tabular} & $\begin{array}{c}2.33 \\
(0.58) \\
\end{array}$ & $\begin{array}{l}15.33 \\
(5.13) \\
\end{array}$ & \begin{tabular}{|c}
1.00 \\
$(1.00)$ \\
\end{tabular} & \begin{tabular}{|c|}
0.33 \\
$(0.58)$ \\
\end{tabular} & $\begin{array}{c}2.00 \\
(1.73) \\
\end{array}$ & $\begin{array}{c}1.33 \\
(1.53) \\
\end{array}$ & \begin{tabular}{|c|c}
4.67 \\
$(1.53)$ \\
\end{tabular} & & \begin{tabular}{|c}
0.33 \\
$(0.58)$ \\
\end{tabular} & & & $\begin{array}{c}0.33 \\
(0.58) \\
\end{array}$ \\
\hline & admin's workstation & 4.16 & 7.76 & & & & & & $\begin{array}{c}0.33 \\
(0.58) \\
\end{array}$ & & $\begin{array}{c}0.33 \\
(0.58) \\
\end{array}$ & & $\begin{array}{c}0.67 \\
(1.16) \\
\end{array}$ & & & & & & & & & & \\
\hline & director's workstation & 4.77 & 7.98 & & & & & & & \begin{tabular}{|c|}
0.33 \\
$(0.58)$
\end{tabular} & \begin{tabular}{|c|}
0.33 \\
$(0.58)$
\end{tabular} & \begin{tabular}{|c|}
0.33 \\
$(0.58)$
\end{tabular} & \begin{tabular}{|c|}
1.00 \\
$(1.00)$
\end{tabular} & \begin{tabular}{|c|}
0.33 \\
$(0.58)$
\end{tabular} & $\begin{array}{c}0.33 \\
(0.58)\end{array}$ & \begin{tabular}{|c|}
0.33 \\
$(0.58)$
\end{tabular} & & $\begin{array}{c}1.00 \\
(1.00)\end{array}$ & & $\begin{array}{l}0.67 \\
(0.58)\end{array}$ & \begin{tabular}{|c|}
0.67 \\
$(0.58)$
\end{tabular} & $\begin{array}{c}0.33 \\
(0.58)\end{array}$ & $\begin{array}{c}1.67 \\
(1.53)\end{array}$ \\
\hline & discussion & 7.40 & 11.88 & & & \begin{tabular}{|c}
0.33 \\
$(0.58)$ \\
\end{tabular} & \begin{tabular}{|c}
0.33 \\
$(0.58)$ \\
\end{tabular} & \begin{tabular}{|c|}
0.67 \\
$(0.58)$ \\
\end{tabular} & & $\begin{array}{c}0.33 \\
(0.58) \\
\end{array}$ & $\begin{array}{c}1.00 \\
(1.73) \\
\end{array}$ & & $\begin{array}{c}1.33 \\
(1.53) \\
\end{array}$ & & $\begin{array}{c}0.67 \\
(1.16) \\
\end{array}$ & \begin{tabular}{|c}
0.33 \\
$(0.58)$ \\
\end{tabular} & & \begin{tabular}{|c|c}
1.00 \\
$(1.73)$ \\
\end{tabular} & & & & & \\
\hline & reception and waiting space & 6.14 & 10.21 & & & & & & & $\begin{array}{c}0.67 \\
(1.16) \\
\end{array}$ & $\begin{array}{c}1.00 \\
(1.73) \\
\end{array}$ & $\begin{array}{c}0.33 \\
(0.58) \\
\end{array}$ & \begin{tabular}{|c|}
2.00 \\
$(3.46)$ \\
\end{tabular} & $\begin{array}{c}0.00 \\
(0)\end{array}$ & $\begin{array}{c}1.00 \\
(1.73) \\
\end{array}$ & \begin{tabular}{|c|}
0.67 \\
$(1.16)$ \\
\end{tabular} & \begin{tabular}{|c|}
0.33 \\
$(0.58)$ \\
\end{tabular} & \begin{tabular}{|c|}
2.00 \\
$(3.46)$ \\
\end{tabular} & & & & & \\
\hline & showroom & 9.08 & 18.11 & & & & \begin{tabular}{|c}
0.33 \\
$(0.58)$ \\
\end{tabular} & $\begin{array}{c}0.33 \\
(0.58)\end{array}$ & & & \begin{tabular}{|c}
0.33 \\
$(0.58)$ \\
\end{tabular} & & $\begin{array}{c}0.33 \\
(0.58) \\
\end{array}$ & \begin{tabular}{|c}
0.33 \\
$(0.58)$ \\
\end{tabular} & & & & \begin{tabular}{|c|}
0.33 \\
$(0.58)$ \\
\end{tabular} & \begin{tabular}{|c|}
0.33 \\
$(0.58)$ \\
\end{tabular} & & & & $\begin{array}{c}0.33 \\
(0.58) \\
\end{array}$ \\
\hline & pantry & 5.93 & 7.22 & & & & & & & & & & & & & & & & & & & & \\
\hline & circulation & 9.05 & 15.03 & $\begin{array}{c}0.33 \\
(0.58)\end{array}$ & & $\begin{array}{c}0.67 \\
(0.58)\end{array}$ & & $\begin{array}{l}1.00 \\
1.00\end{array}$ & \begin{tabular}{|c|}
0.33 \\
$(0.58)$ \\
\end{tabular} & $\begin{array}{c}0.33 \\
(0.58)\end{array}$ & $\begin{array}{c}1.00 \\
(1.00)\end{array}$ & $\begin{array}{c}0.33 \\
(0.58)\end{array}$ & \begin{tabular}{|c}
2.00 \\
$(1.73)$
\end{tabular} & $\begin{array}{c}0.67 \\
(0.58)\end{array}$ & $\begin{array}{c}0.33 \\
(0.58)\end{array}$ & \begin{tabular}{|c}
0.33 \\
$(0.58)$
\end{tabular} & & \begin{tabular}{|c|}
1.33 \\
$(1.16)$
\end{tabular} & & & & & \\
\hline
\end{tabular}

*value in mean frequency (time/day), empty boxes shows no communication occurred at particulat spaces and time clusters indicate high communication occurrences

indicate integrated space

For the third objective (see Figure 7), a cross analysis was conducted to compare the communication occurrences between specific spaces with their spatial properties, focusing on the factors of accessibility and visibility (Figure 7). Median values were used to set apart the integrated and segregated spaces in both organizations. We considered the integrated spaces to have higher possibilities for communication occurrences since the locations allowed people to go anywhere (accessibility factor) and to easily see others individuals (visibility factor). The median value for ORG 1 -accessibility was Int. $\mathrm{V}>5.02$, while the visibility value was, Int.V $>11.06$, meanwhile, the median value for ORG 2-accessibility was Int.V $>6.46$ while visibility was Int.V $>11.05$. The results showed that ORG 1 had higher communication frequency for visibility, but not accessibility at studio workstations, which were located in integrated spaces. Most communications in ORG 1 had occurred during the combination 
processes. The same pattern was also observed from the results for ORG 2, where there was high communication frequency at the designer workstations for both accessibility and visibility because the spaces were located in an integrated area. Most communication also occurred during the combination processes. From the graphs, the observation results showed a low frequency of SECI communications that occurred in segregated spaces such as the pantry, library, photocopier, material preparation space, and other divisions like QS or administration. There were also moderate communication occurrences in both segregated and integrated spaces such as the discussion spaces, circulation areas, director's room, showroom, and reception/waiting spaces. Based on these data, the results showed that SECI communications do occurred in all integrated spaces, even though the frequency values were not high.
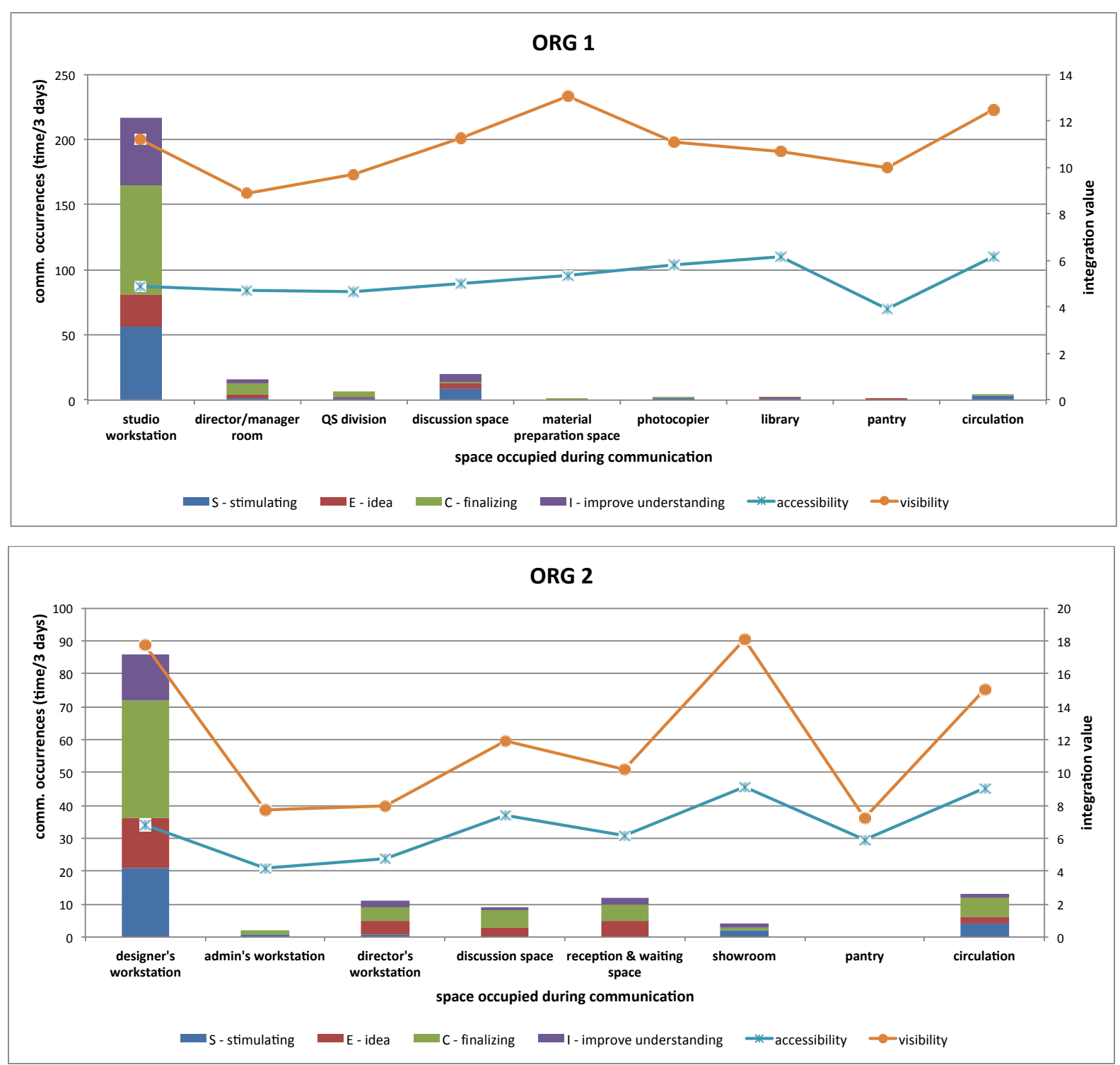

Figure 7. Cross analysis graph comparing VGA integration values of spaces and the AOC of SECI behaviors in spatial usage

\section{Conclusion}

This study has identified communicative environments for SECI behaviors by measuring communication occurrences while the designers are performing the expected behaviors. In this study, it was ascertained that space usage differed when designers are communicating among themselves during the knowledge creation behaviors related to creativity. The findings regarding spatial configurations fostering knowledge creation behaviors can be summarized as follow: 
1) Communication among organizational members while performing knowledge creation behaviors mostly occurred in both the integrated and segregated spaces.

2) Communication regarding knowledge creation behaviors frequently occurred in both integrated and segregated spaces when considering the "visibility" factor; however, communication with longer duration mostly occurred in segregated spaces when considering the "accessibility" factor.

Meanwhile, the findings that highlighted the relationship between knowledge creation behaviors within social networks and spatial usage can be summarized as follows:

1) Socialization communication had high AOC in service territories $(61.5 \%)$ where the most communication occurred among senior designers (30.25\%).

2) Externalization communication had high AOC in individual working territories $(54.5 \%)$ where the most communication occurred among superior designers (44.9\%).

3) Combination communication had high AOC in individual working territories $(62.5 \%)$ where the most communication occurred between superior designers and senior designers $(25.8 \%)$, senior designers and junior designers (35.6\%), and among junior designers (44.0\%).

4) Internalization communication had high $\mathrm{AOC}$ in individual working territories $(60 \%)$ where the most communication occurred between junior designers and senior designers (35.6\%).

\section{Acknowledgments}

This research was supported by MEXT, Japan.

\section{References}

Girdauskiene, L. (2013). The Key Factors for Creativity Implementation and Knowledge Creation in an Organization: The Structural Approach. Economics \& Management, 18(1), 176-182. http://dx.doi.org/10.5755/j01.em.18.1.4305

Greene, C., \& Myerson, J. (2011). Space for Thought: Designing for Knowledge Workers. Facilities, 29(1/2), 19-30. http://dx.doi.org/10.1108/02632771111101304

Gurteen, D. (1998). Knowledge, Creativity and Innovation. Journal of Knowledge Management, 2(1), 5-13. http://dx.doi.org/10.1108/13673279810800744

Häkkinen, T., \& Nuutinen, M. (2007). Seeking Sustainable Solutions for Office Buildings. Facilities, 25(11/12), 437-451. http://dx.doi.org/10.1108/02632770710822553

Hatch, M. J. (1987). Physical Barriers, Task Characteristics and Interaction Activity in Research and Development Firms. Administrative Science Quarterly, 32, 387-399. http://dx.doi.org/10.2307/2392911

Kallio, T. J., Kallio, K.-M., \& Blomberg, A. J. (2015). Physical Space, Culture and Organisational Creativity ALongitudinal Study. Facilities, 33(5/6), 389-411. http://dx.doi.org/10.1108/F-09-2013-0074

Koh, A. (2000). Linking Learning, Knowledge Creation, and Business Creativity: A Preliminary Assessment of the East Asian Quest for Creativity. Technological Forecasting and Social Change, 64(1), 85-100. http://dx.doi.org/10.1016/S0040-1625(99)00075-X

Kristensen, T. (2004). The Physical Context of Creativity. Creativity and Innovation Management, 13(2), 89-96. http://dx.doi.org/10.1111/j.0963-1690.2004.00297.x

Large, R. O. (2005). Communication Capability and Attitudes toward External Communication of Purchasing Managers in Germany. International Journal of Physical Distribution \& Logistics Management, 35(6), 426444. http://dx.doi.org/10.1108/09600030510611657

Leenders, R. T. J., Van Engelen, J. M. L., \& Kratzer, J. (2003). Virtuality, Communication, and New Product Team Creativity: A Social Network Perspective. Journal of Engineering and Technology Management (JET-M), 20(1-2 SPEC.), 69-92. http://dx.doi.org/10.1016/S0923-4748(03)00005-5

Martens, Y. (2011). Creative Workplace: Instrumental and Symbolic Support for Creativity. Facilities, 29(1/2), 63-79. http://dx.doi.org/10.1108/02632771111101331

Mueller, B. H., \& Lee, J. (2002). Leader-Member Exchange and Organizational Communication Satisfaction in Multiple Contexts. Journal of Business Communication, 39(2), 220-244. http://dx.doi.org/10.1177/002194360203900204

Nonaka, I., \& Takeuchi, H. (1995). The Knowledge Creating Company. Oxford University Press, Inc. 
Oldham, G. R., \& Rotchford, N. L. (1983). Relationships between Office Characteristics and Employee Reactions: A Study of the Physical Environment. Administrative Science Quarterly, 28(4), $542-556$. http://dx.doi.org/10.2307/2393008

Sailer, K. (2011). Creativity as a Social and Spatial Process. Facilities, 29(1/2), 6-18. http://dx.doi.org/10.1108/02632771111101296

Stryker, J. B., Santoro, M. D., \& Farris, G. F. (2012). Creating Collaboration Opportunity: Designing the Physical Workplace to Promote High-Tech Team Communication. IEEE Transactions on Engineering Management, 59(4), 609-620. http://dx.doi.org/10.1109/TEM.2011.2170995

Toker, U., \& Gray, D. O. (2008). Innovation Spaces: Workspace Planning and Innovation in U.S. University Research Centers. Research Policy, 37(2), 309-329. http://dx.doi.org/10.1016/j.respol.2007.09.006

Woodman, R. W., Sawyer, J. E., \& Griffin, R. W. (1993).Toward a Theory of Organizational Creativity. Academy of Management Review, 18(2), 293-321.

Zimmermann, S., Sypher, B. D., \& Haas, J. W. (1996). A Communication Metamyth in the Workplace: The Assumption that More is Better. Journal of Business Communication, 33(2), $185-204$. http://dx.doi.org/10.1177/002194369603300206

\section{Copyrights}

Copyright for this article is retained by the author(s), with first publication rights granted to the journal.

This is an open-access article distributed under the terms and conditions of the Creative Commons Attribution license (http://creativecommons.org/licenses/by/3.0/). 